\title{
Topography- and nightlight-based national flood risk assessment in Canada
}

\author{
Amin Elshorbagy $^{1,2}$, Raja Bharath ${ }^{1}$, Anchit Lakhanpal ${ }^{1}$, Serena Ceola ${ }^{3}$, Alberto Montanari ${ }^{3}$, and \\ Karl-Erich Lindenschmidt ${ }^{2,4}$ \\ ${ }^{1}$ Department of Civil, Geological, and Environmental Engineering, University of Saskatchewan, \\ Saskatoon, Canada \\ ${ }^{2}$ Global Institute for Water Security, University of Saskatchewan, Saskatoon, Canada \\ ${ }^{3}$ Department of Civil, Chemical, Environmental, and Materials Engineering, University of Bologna, \\ Bologna, Italy \\ ${ }^{4}$ School of Environment and Sustainability, University of Saskatchewan, Saskatoon, Canada
}

Correspondence to: Amin Elshorbagy (amin.elshorbagy@usask.ca)

Received: 3 October 2016 - Discussion started: 19 October 2016

Revised: 22 March 2017 - Accepted: 22 March 2017 - Published: 26 April 2017

\begin{abstract}
In Canada, flood analysis and water resource management, in general, are tasks conducted at the provincial level; therefore, unified national-scale approaches to waterrelated problems are uncommon. In this study, a nationalscale flood risk assessment approach is proposed and developed. The study focuses on using global and national datasets available with various resolutions to create flood risk maps. First, a flood hazard map of Canada is developed using topography-based parameters derived from digital elevation models, namely, elevation above nearest drainage (EAND) and distance from nearest drainage (DFND). This flood hazard mapping method is tested on a smaller area around the city of Calgary, Alberta, against a flood inundation map produced by the city using hydraulic modelling. Second, a flood exposure map of Canada is developed using a land-use map and the satellite-based nightlight luminosity data as two exposure parameters. Third, an economic flood risk map is produced, and subsequently overlaid with population density information to produce a socioeconomic flood risk map for Canada. All three maps of hazard, exposure, and risk are classified into five classes, ranging from very low to severe. A simple way to include flood protection measures in hazard estimation is also demonstrated using the example of the city of Winnipeg, Manitoba. This could be done for the entire country if information on flood protection across Canada were available. The evaluation of the flood hazard map shows that the topography-based method adopted in this study is
\end{abstract}

both practical and reliable for large-scale analysis. Sensitivity analysis regarding the resolution of the digital elevation model is needed to identify the resolution that is fine enough for reliable hazard mapping, but coarse enough for computational tractability. The nightlight data are found to be useful for exposure and risk mapping in Canada; however, uncertainty analysis should be conducted to investigate the effect of the overglow phenomenon on flood risk mapping.

\section{Introduction}

Rivers, and water bodies in general, have always been the most attractive landscape feature for humankind. Historically and to date, rivers have provided people with water for drinking and agriculture, food, an inexpensive mode of transportation, a natural drain for their effluents, and fertile land for agriculture in the floodplains. Consequently, most populous cities in the world are built around rivers. Interestingly, even recent studies show that people are still moving closer to streams in various regions of the world (Ceola et al., 2015). The increased flood hazard comes as a natural consequence of encroaching on floodplains.

Globally, floods are among the most feared natural hazards as they can inflict large-scale economic and social damage, cause panic, and disrupt essential services. Annually, thousands of lives are lost due to floods, with 5200 lives, for 
example, claimed in 2011 alone (Balica et al., 2013). The most recent 2016 floods in Louisiana, USA, claimed 13 lives and left 40000 homes under water. In Canada, flood damages have exceeded USD 7.4 billion over the recent 5 years (20102015), with nine lives lost and more than 100000 individuals directly affected, according to the CRED/OFDA International Disaster Database (http://www.emdat.be/database). This has led the Canadian government to establish FloodNet - a Canada-wide strategic research network for flood forecasting and impact assessment.

Floodplains and low-lying lands are typically areas with high levels of flood hazard due to their elevation and proximity to rivers; however, society makes such areas more exposed by inhabiting them and establishing valuable economic investments, with insufficient measures to contain vulnerability in most cases and thus increasing flood risk as a product of hazard, exposure, and vulnerability (Balica et al., 2013; UNISDR, 2009; Samuels et al., 2009), which is discussed in detail in Sect. 2. It has been suggested that social memory plays a significant role in flood vulnerability as societal preparedness can be different based on the recent history of floods. Some argue that areas that have not been flooded for a long time tend to be encroached by the society, causing the damage from future floods to be higher than expected, whereas areas that were recently damaged by floods seem to encounter lower than expected damages when another flood occurs (Di Baldassarre et al., 2015). This emphasises the importance of developing a systematic flood risk assessment approach that helps societies, insurance companies, water managers, and policy makers make informed decisions.

National flood risk assessment approaches are useful but challenging as data required to develop realistic approaches can be extensive, and detailed hydraulic modelling without proper prioritization of high-risk areas can be unjustifiably costly. In recent years, there has been an increasing use of remotely sensed and global datasets in water resources as they can make such studies on a national scale possible. For example, GRACE (the Gravity Recovery and Climate Experiment) has been shown to provide data on water cycles and groundwater reserves that are needed for water management (Famiglietti and Rodell, 2013). Satellite-based data, e.g. snow cover data, have proven valuable for calibrating hydrological models (Parajka and Blöschl, 2008) and for flood detection and mapping (Brakenridge and Anderson, 2006). Ceola et al. $(2014,2015)$ used $1 \mathrm{~km}$ resolution nightlight datasets to show human interaction with streams as well as exposure to floods, based on the fact that nightlights reflect human activities. As nightlights can indicate the spatial distribution and temporal trends, in certain regions, of human activities around rivers, we reiterate that they are of obvious relevance to flood risk assessment studies, especially on a large scale.

Ceola et al. (2014) relied mainly on the proximity of population to rivers to assess exposure to floods. However, a research question that has been left unaddressed by previous studies that used nightlights relates to the datasets that are needed, in combination with nightlights, to establish flood risk assessment approaches that are realistic and feasible. The aim of this study is to integrate several and relevant sources of information to develop a flood risk assessment approach for Canada, which will lead to national flood hazard and risk maps that benefit from topographic information, remotely sensed nightlight data, and, as an option, local information to estimate vulnerability. The end product should be flexible, easily updatable, and help stakeholders assess areas that require further attention through, for example, detailed hydraulic modelling.

\section{Flood hazard, exposure, vulnerability, and risk}

The terms of flood hazard, exposure, vulnerability, and risk are sometimes confusing to readers as they may have different meanings for different users. The four terms may even be used interchangeably to refer to the same thing. Following the definition provided by UNISDR (2009), IPCC (2012), and Colleantuer et al. (2015), flood risk is given by a combination (e.g. the product) of hazard, exposure, and vulnerability (Eq. 1).

Flood risk $=$ flood hazard $\times$ flood exposure

$$
\times \text { flood vulnerability }
$$

Hazard is used by some researchers to mean the flood disaster itself or its potential occurrence (Gilard, 2016; UNISDR, 2009; Colleantuer et al., 2015), identified more precisely (Sayers et al., 2002) by two main components - source (e.g. rain) and pathway (e.g. flood extent and depth). This definition is appropriate and usually quantified from an engineering perspective as the probability of occurrence of a flood event (Balica et al., 2013; de Moel et al., 2009). Intuitively, a low-lying area that is close to a river has a higher level of flood hazard (impacted by more frequent floods) than an area of higher elevation that is far removed from the river. In this study, distance from and elevation above the river are used as two indicators of the flood hazard level of any land pixel.

Exposure (i.e. elements at risk) is given by the economic and intrinsic values that are present at the location involved (IPCC, 2012). Population density, capital investment, and land or property value can be indicators of flood exposure. Vulnerability, following Adger (2006) and Colleantuer et al. (2015), is defined as the capacity of the society to deal with the flood event, namely, the state of susceptibility to harm from exposure to an undesired event, floods in this study, associated with environmental and social change, and lack of capacity to adapt. Lack of flood defences or protection of economic values and human lives susceptible to floods are indicators of vulnerability. Obviously, the product of exposure and vulnerability reflects an integrated measure of the environmental and socioeconomic consequences of floods. The main reason for the increase in losses due to 


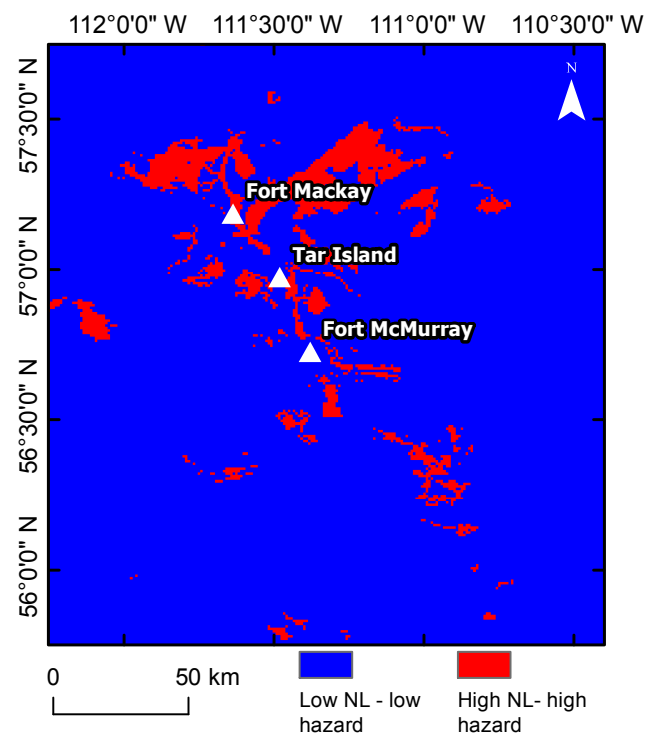

Figure 1. Locations indicating increase in nightlight (NL) activity over high-hazard areas between the years 1992 and $2013\left(\mathrm{DN}_{2013}{ }^{-}\right.$ $\mathrm{DN}_{1992}$ ).

floods is the increase in the population and people's preference to reside in flood prone areas, which exposes them to floods (Jonkman, 2005; Ceola et al., 2014). An example of the policy and social dimension of exposure is depicted in Fig. 1 for the city of Fort McMurray, Alberta, Canada, and its surrounding areas, which shows how the society encroached into areas of a higher level of flood hazard over the years. An increase in exposure is indicated by the spatial expansion and increase in nightlight luminosity from 1999 to 2013, which is considered a proxy for socioeconomic activities (Doll et al., 2000), overlaid with the flood hazard map showing only high-hazard areas. The hazard was calculated based on elevation above and distance from the nearest rivers, details of which are provided in the forthcoming sections. The figure is obtained after combining and reclassifying the two maps to show that significant development has occurred over the years in high-hazard areas.

In the literature, frameworks or guidelines for flood risk assessment at the national level are limited. A classic example is the work of Hall et al. (2005), who conducted a national-scale flood risk assessment in England and Wales for the purpose of prioritization of resources for flood management. The methodology of Hall et al. (2005) benefited from rich information available on the standard of protection, condition and location of flood defences, as well as flood extent maps, occupancy, and asset values in England and Wales. de Moel et al. (2009) noted that flood extent maps are the most commonly produced flood maps in Europe, and that only very few countries have developed flood risk maps that comply with the European Directive (2007/60/EC). Later, Lugeri et al. (2010) developed a flood hazard map of Europe, identifying low-lying areas adjacent to rivers, and used it with land-use data and a damage-stage relationship to identify flood risk. A coarse global-scale flood risk assessment was also developed by Ward et al. (2013) using global hydrological and hydraulic modelling. The work presented in this paper is at a finer resolution, and using different types of data based on topography and remote sensing, which lead to a low-cost flood-mapping product that is relevant at a national scale.

The level of detail required for flood risk analysis is an important issue, which is obviously related to the spatial scale of the study area. Even in urban areas, Apel et al. (2009) found that a medium-level complexity model for both hazard and exposure is sufficient. One could expect that on a national scale for large countries, aggregate measures and index-based approaches might be the feasible choice. When compared with a physically based modelling approach, a parametric approach, which uses flood hazard and exposure indices, can direct decision makers to simplified usage and simpler understanding of the risk and thus better allocation of resources and investments for flood management and protection (Balica et al., 2013).

As the second largest country in the world, the continental extent of Canada from 41.7 to $83.111^{\circ} \mathrm{N}$ and from 52.619 to $141.010^{\circ} \mathrm{W}$, encompasses different topographies ranging from flat prairies to mountains and different climates from semi-arid to wet. On an average annual basis, Canadian rivers discharge $9 \%$ of the world's renewable water resources (Whitfield and Cannon, 2000). Fluvial floods in Canada can happen as a result of excessive rainfall, similar to the 2013 flood in Alberta; however, high water levels often result from reduced channel capacity due to ice and debris jams (NRCC, 1989). Therefore, water levels and extent of floods may not reflect the conventional return period associated with the flood discharge. Floods are usually monitored, analysed, and managed at the provincial level, which makes a Canada-wide unified flood modelling, mapping, and analysis, as well as flood-related data accessibility, a laborious tasks.

\section{Material and methods}

To develop a national-scale framework for flood risk assessment in Canada, parameters representing the concepts of hazard and exposure were identified and, subsequently, a flood risk index was developed based on the integration of both hazard and exposure. All three types of maps - hazard, exposure, and risk - are presented separately as they each contain distinct and useful information. In a subsequent step that is developed for the city of Winnipeg, Manitoba, we show how flood protection measures, as might be represented within hazard or vulnerability, can be incorporated. 


\subsection{Hazard parameters and mapping}

It is common to define and classify flood hazard based on flood magnitude and/or frequency (Apel et al., 2009; Balica et al., 2013), but classification based on depth is also used (Masood and Takeuchi, 2012). The frequency and magnitude of floods, along with their associated inundation depth, are constantly changing due to economic development and climate change (Milly et al., 2002), which challenges the estimates and definition of flood hazard and risk on a range of scales (Merz et al., 2010). Therefore, classifying hazard levels on a national scale based on topography (Lugeri et al., 2010) is both realistic and sound, as it can be converted locally to other types of classification as will be discussed here in the results section.

In this study, flood hazard was estimated using two parameters: elevation above the nearest drainage (EAND), which is similar to HAND (height above nearest drainage; Rennó et al., 2008) and distance from the nearest drainage (DFND). These two parameters define the topography of an area and thus help in determining the relative position of a place with respect to the stream. Both parameters were derived from a Canadian digital elevation model (DEM) obtained from Natural Resources Canada (http://geogratis.gc.ca/site/ eng/extraction). The Canadian DEM is derived from the Canadian Digital Elevation Data, which were extracted from the hypsographic and hydrographic elements of the National Topographic Data Base, the Geospatial Database, various scaled positional data acquired by the provinces and territories, or remotely sensed imagery. The Canadian DEM is available for download at various resolutions ranging from $0.75 \operatorname{arcsec}(\sim 20 \mathrm{~m}$ at the Equator) to $12 \operatorname{arcsec}(\sim 326 \mathrm{~m}$ at the Equator) as tiles that are consistent with the National Topographic System; Official division and identification system for the base topographic maps of Canada). Both the 20 and $326 \mathrm{~m}$ DEM resolutions were assessed in this study. The vertical accuracy of the DEM varies with location, with a measured altimetry accuracy of under $5 \mathrm{~m}$ per tile for most parts of the country (Natural Resources Canada, 2016).

EAND is a terrain descriptor, which produces a new normalised DEM where pixel values represent altitudes relative to the local drainage instead of the mean sea level. To allocate elevation values to the pixels with respect to local drainage, we first identified the drainage network by using the ArcGIS hydrology tool. The DEM, available in raster format, was initially filled by identifying pits and raising their elevation to the level of the lowest pour point. After obtaining the filled DEM, the second step was to generate flow direction. There are a total of eight valid output flow directions, corresponding to the eight adjacent cells into which water may flow. The flow direction tool follows the eight-direction flow model, which was presented by Jenson and Domingue (1988). After identifying the drainage network for Canada, a new raster was created using the Euclidean allocation tool available in the spatial analyst toolbox of ArcGIS. All pixels within this raster were assigned the new values of elevation, which were the elevation values of the nearest drainage pixel based on Euclidean distance. Finally, this output was subtracted from the original elevations to obtain the EAND map for the study area. Also, for each pixel, the DFND - the horizontal distance from the nearest drainage network - was calculated. Negative values of EAND could be observed because there were depressions lower than the nearest stream. EAND and DFND were classified into five different EAND and DFND classes as shown in Table 1. The lower values of EAND and DFND were assigned the higher class values as they indicate the low-lying and close areas to the streams, respectively, and thus the highest level of flood hazard. The hazard value was calculated based on the product of EAND and DFND classes; e.g. a hazard level of 20 could result from EAND class 4 and DFND class 5 (or vice versa). Finally, hazard values were reclassified into five different hazard classes as shown in Table 1 . The class intervals were selected somewhat arbitrarily in this study. However, depending on the topography of the study area, other hazard class intervals can be selected.

The topography-based hazard-mapping approach, developed in this study, was validated quantitatively against a flood inundation map developed using hydraulic modelling by the city of Calgary (Government of Alberta, 2013) for an area of Calgary. Validation is meant to assess that the product does provide useful information for locating the areas at higher flood hazard (Biondi et al., 2012). Two performance measures were selected for validation: sensitivity and specificity (Altman and Bland, 1994). Sensitivity and specificity are measures that indicate the probability of correctly classifying a pixel within the flooding extent as flooded or nonflooded. The measures are easy to calculate and have been used in classification studies in the past (e.g. Murtaugh, 1996; Cutler et al., 2007). Sensitivity $\left(S_{v}\right)$ is defined as

$$
\begin{aligned}
S_{v} & =\frac{F_{\mathrm{p}}}{F_{\mathrm{ap}}}, \\
S_{v} & =\frac{F_{\mathrm{p}}}{F_{\mathrm{p}}+F_{\mathrm{op}}},
\end{aligned}
$$

where $F_{\mathrm{p}}, F_{\mathrm{ap}}$, and $F_{\mathrm{op}}$ are the number of truly predicted flooded pixels, the total number of actually flooded pixels, and the number of pixels actually flooded that were predicted as not flooded, respectively. Here, "truly predicted" refers to the pixels in the hazard level severe in the hazard map, and "actually" refers to pixels in the flood inundation map used for validation. $S_{v}$ ranges from 0 to 1 , with values closer to 1 indicating a high probability of correctness in classifying a flooded pixel. Specificity $\left(S_{c}\right)$ is defined as

$$
\begin{aligned}
S_{c} & =\frac{\mathrm{NF}_{\mathrm{p}}}{\mathrm{NF}_{\mathrm{ap}}}, \\
S_{c} & =\frac{\mathrm{NF}_{\mathrm{p}}}{\mathrm{NF}_{\mathrm{p}}+\mathrm{NF}_{\mathrm{op}}},
\end{aligned}
$$


Table 1. Classes of elevation above nearest drainage (EAND), distance from nearest drainage (DFND), and the resultant flood hazard for Canada.

\begin{tabular}{lrrrrrl}
\hline EAND $(\mathrm{m})$ & Class & DFND $(\mathrm{m})$ & Class & Hazard & Class & Hazard level \\
\hline$\leq 2.0$ & 5 & $\leq 1000$ & 5 & $21-25$ & 5 & Severe \\
$2.1-4$ & 4 & $1001-2500$ & 4 & $16-20$ & 4 & High \\
$4.1-6$ & 3 & $2501-5000$ & 3 & $11-15$ & 3 & Medium \\
$6.1-8$ & 2 & $5001-10000$ & 2 & $6-10$ & 2 & Low \\
$>8.0$ & 1 & $>10000$ & 1 & $1-5$ & 1 & Very low \\
\hline
\end{tabular}

where $\mathrm{NF}_{\mathrm{p}}, \mathrm{NF}_{\mathrm{ap}}$, and $\mathrm{NF}_{\mathrm{op}}$ are the number of truly predicted not-flooded pixels, the total number of actually notflooded pixels, and the number of pixels actually not-flooded that were predicted as flooded, respectively. $S_{c}$ ranges from 0 to 1 where values closer to 1 indicate a high probability of correctness in classifying a pixel as a non-flooded pixel. A qualitative assessment of the flood hazard mapping was also conducted against an aerial flood photo in Saskatchewan, Canada. Another important parameter that affects the flood and its impact on the floodplain is the existence of flood protection or defence measures. Including flood protection within hazard or vulnerability can be debatable. However, the approach we adopt in this study depends on the type of the flood protection. Structural flood protection measures that affect the flood runoff itself (Mays, 2015), such as dikes and dams, are included within hazard assessment as they affect the flood stage-discharge and discharge-frequency relationships. Non-structural measures, such as zoning, insurance, rearranging spaces, and raising buildings, are included within vulnerability assessment because they affect the susceptibility of the floodplain (UNISDR, 2009) rather than the flood water (Mays, 2015). When such information on flood protection is available for the whole country, flood protection can be included as the third hazard parameter to identify the final hazard level or as a separate vulnerability parameter. Flood protection can be included as a binary parameter, i.e. protected/unprotected, or in the form of various levels of protection. For the current study, complete information on flood protection across Canada was not made available to us; however, we investigated how to consider protection on a smaller regional scale around the city of Winnipeg, Manitoba, and it will be shown in the results section.

\subsection{Exposure parameters and mapping}

As reflected in most flood studies, there is no doubt that land-use is the most relevant flood exposure parameter as it indicates the land or property value, e.g. urban development or agricultural land. In this study we also used a landuse map for Canada available through the North American Land Change Monitoring System (NALCMS; Latifovic et al., 2012), which is available in raster format at a spatial resolution of $250 \mathrm{~m}$ and can be obtained through http://www. cec.org/tools-and-resources/map-files/land-cover-2005. The original land-use data taken from NALCMS define 19 landuse types for North America, out of which there are 15 types found in Canada. These types were further reclassified for the purpose of this study into five types as shown in Table 2 . There are no agreed upon global rules for land-use classification; however, for the purpose of national-scale flood risk assessment, these five types were judged to be sufficient, and also bear some similarity to the European Corine Land Cover classes (http://uls.eionet.europa.eu/CLC2006/CLC_Legeng. pdf). The reclassified land-use types were then assigned values between 1 and 5 according to their economic value, with the values of 5 and 1 assigned to urban areas and water bodies, respectively.

The second flood exposure parameter considered in this study is nightlights. Nightlight satellite imagery has been investigated as a proxy for human activities, and has been used in various studies for different domains (Raupach et al., 2010; Zhou et al., 2014; Gómez et al., 2015; Townsend and Bruce, 2010). Ceola et al. (2014) explored nightlights to examine human exposures to floods worldwide, using HydroSHEDS data, based only on proximity to streams. The study included 175 regions covering 168 countries with the exception of Canada, Russia, and part of northern Europe. The nightlight values, defined by a digital number (DN) ranging from 0 to 63 to reflect the degree of luminosity, were classified for Canada into five different nightlight classes (NC) as shown in Table 3. The nightlight data were obtained from the National Oceanic and Atmospheric Administration of the United States (http://ngdc.noaa.gov/eog/dmsp/ downloadV4composites.html). The spatial resolution of the dataset is 30 arcsec (corresponds to roughly $1 \mathrm{~km}$ near the Equator, and around $600 \mathrm{~m}^{2}$ over populous southern Canada) and the data are available for the period 1992-2013. When datasets with multiple spatial resolutions were used, the maps with coarser resolution were resampled to correspond with the finer resolution, and thus the final product has the finer resolution. The most recent available data of 2013 were used for our analysis, and the Canadian nightlight map of the year 2013 is shown in Fig. 2.

The ranges of the first two classes (having $\mathrm{DN} \leq 10$ ) were kept narrow because they are spread over the most part of Canada (about $98 \%$ of Canada's area). They indicate absent or low human activity and, hence, from a flood exposure per- 
Table 2. Classes of land-use types in Canada along with their percent of area covered.

\begin{tabular}{llrr}
\hline Land-use type & $\begin{array}{l}\text { Reclassified } \\
\text { land-use }\end{array}$ & $\begin{array}{r}\text { Land-use class } \\
\text { (LC) }\end{array}$ & $\begin{array}{r}\% \text { of area } \\
\text { covered }\end{array}$ \\
\hline $\begin{array}{l}\text { - Wetland (marshes, swamps, mangroves) } \\
\text { - Water (open water) }\end{array}$ & Water bodies & 1 & 16 \\
- Snow and Ice (perennial cover) & & 2 & 28.2 \\
\hline $\begin{array}{l}\text { - Barren land } \\
\text { - Sub polar or polar barren moss }\end{array}$ & Wasteland/ grassland & \\
- Temperate or sub-polar grassland & & & \\
- Sub polar or polar grassland & & 3 & 50 \\
\hline - Temperate or subpolar needle leaf forest & Forest & & \\
- Temperate or subpolar broad leaf forest & & & \\
- Mixed forest & & & \\
- Temperate or subpolar shrub land & & 4 & 5.7 \\
\hline Subpolar or polar shrub land & & 5 & 0.1 \\
\hline Cropland & Agriculture & & \\
\hline Urban and built-up & Urban & & \\
\hline
\end{tabular}

Table 3. Classes of nightlight luminosity in Canada from 1 to 5. The exposure classes were selected based on the product of nightlight and land-use classes.

\begin{tabular}{lllrrrl}
\hline $\begin{array}{l}\text { Nightlight } \\
\text { value (DN) }\end{array}$ & $\begin{array}{l}\text { Nightlight } \\
\text { class (NC) }\end{array}$ & Nightlight level & $\begin{array}{r}\% \text { area } \\
\text { covered }\end{array}$ & Exposure & Class & $\begin{array}{l}\text { Exposure } \\
\text { level }\end{array}$ \\
\hline $0-5$ & 1 & Very low luminosity & 93.6 & $1-5$ & 1 & Very low \\
$6-10$ & 2 & Low luminosity & 4.4 & $6-10$ & 2 & Low \\
$11-30$ & 3 & Medium luminosity & 1.4 & $11-15$ & 3 & Medium \\
$31-59$ & 4 & High luminosity & 0.5 & $16-20$ & 4 & High \\
$60-63$ & 5 & Very high luminosity & 0.1 & $21-25$ & 5 & Severe \\
\hline
\end{tabular}

spective they are less important. Accordingly, low nightlight class values were assigned to them. The range of DN values 11-30 is significant as it is mainly found in parts of the forest and agricultural land that possess more important resources than the first two classes. The DN range of 31-59 is found in the outskirts of cities and towns, and represents mostly agricultural lands and small establishments. The pixels having DN values of 60 and above fall within city boundaries and contribute up to $80 \%$ of the nightlights of the city. Therefore, 60 and above were kept as a separate class $(\mathrm{NC}=5)$, highlighting urban centres, which are the most flood exposed areas. Similar to the calculation of the hazard index, exposure was also calculated as the product of land-use and nightlight classes, leading to values ranging from 1 to 25 . The exposure values were further reclassified into five classes as shown in the last three columns of Table 3, and a flood exposure map of Canada was produced.

Finally, and based on Eq. (1), flood risk was calculated as the product of hazard and exposure, as local vulnerability information was not available, and was reclassified into five risk classes as shown in Table 4 . In the absence of population data, nightlights might be taken as a surrogate for pop- ulation. However, our investigation reveals that both datasets may differ in some places. This is expected as nightlights are more representative of economic investment and activities, which can be different from population. For example, airports and industrial and commercial areas are highly luminous but the census data show low or no population. $\mathrm{Hu}-$ man harm can still happen in areas indicated by census data as "zero-population". The nightlight data capture such areas. However, population data, especially when associated with qualifiers regarding different groups and income can be distinctively used to assess social vulnerability or exposure to floods (Adger, 1999). As floods may have different impacts on the relative well-being of individuals and groups, which is not reflected by classic economic exposure, it is important to identify the impact of floods on population separately, without integrating or averaging with other exposure parameters. Therefore, in this study the physical flood risk map of Canada was produced first, then it was overlaid with the population information to allow for reclassification of the risk map based on the distribution of population. 


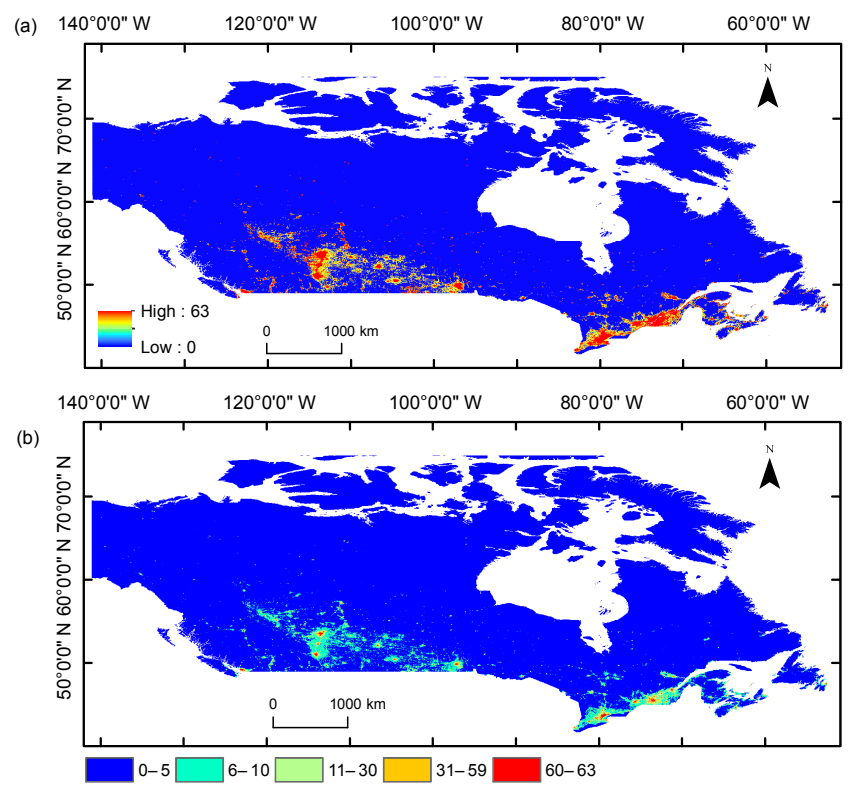

Figure 2. Nightlights over Canada shown as (a) continuous spectrum and (b) classified as shown in Table 3 into very low luminosity (0-5), low luminosity (6-10), medium luminosity (11-30), high luminosity (31-59), and very high luminosity (60-63).

Table 4. Classes of flood risk in Canada, which results from the product of hazard and exposure.

\begin{tabular}{lrl}
\hline $\begin{array}{l}\text { Flood risk } \\
\text { value }\end{array}$ & $\begin{array}{r}\text { Risk class } \\
(\mathrm{RC})\end{array}$ & $\begin{array}{l}\text { Risk level } \\
(\mathrm{RL})\end{array}$ \\
\hline $1-5$ & 1 & Very low \\
$6-10$ & 2 & Low \\
$11-15$ & 3 & Medium \\
$16-20$ & 4 & High \\
$21-25$ & 5 & Severe \\
\hline
\end{tabular}

\section{Results}

\subsection{Flood hazard mapping}

The topography-based (EAND and DFND) flood hazard map of Canada, developed and classified based on the method explained in the previous section, is shown in Fig. 3. Large areas of the country are classified under high and severe levels of flood hazard due to their low elevation and proximity to rivers. However, most of these areas have negligible human presence and economic investments. The flood hazard map can be useful for large-scale planning and development, where avoiding encroachment into flood hazardous area is recommended. In support of identifying the flood information needed for flood insurers to assess their exposure to floods and to price the flood elements at risk, Sanders et al. (2005) identified the availability of fine-resolution DEMs as the key obstacle for such analysis. For the national-scale analysis in this study, we tested the DEM-326, as it is computationally tractable for a country like Canada. However, a comparison between hazard mapping using the DEM-326 and DEM-20 was conducted on a smaller area around the city of Calgary, Alberta. Even though an overall reasonable visual match between both flood hazard maps produced using the different resolutions was found, there were important differences. The stream network itself, generated using the DEMs, have significant differences, and a more realistic representation of the rivers, compared to ground truth, was achieved using DEM-20. All maps in this study were, thus, produced using the DEM-20.

A flood inundation map of an area in the city of Calgary was produced by the city (Government of Alberta, 2013), based on a 100-year flood determined by flood frequency analysis and using the hydraulic model HEC-RAS. This map was prepared for the reaches of Bow and Elbow rivers flowing through the city limits. A comparison between the topography-based flood hazard mapping method adopted in this study and the hydraulic-modelling-based 100-year inundation map is shown in Fig. 4. Visually, there is good agreement between the model-based 100-year flood inundation (shown as hatched grey area) and the hazard level classified in this study as severe (Table 1). Two sections of the reaches are enlarged, as examples, for better visual comparison between both methods. As shown in the main map (on top) in Fig. 4, there is good agreement in other sections as well, and there are small areas that do not match well. Some smaller areas of the 100-year flood are extended over the second-highest hazard area defined in this study as high. This was expected, as our classes shown in Table 1 were selected somewhat arbitrarily across Canada. This agreement between the two maps were further analysed based on performance indices (Eqs. 1 and 2) to quantify the agreement between the inundation map and the hazard level severe. The sensitivity $\left(S_{v}\right)$ was found to be 0.75 indicating that the hazard class severe is able to capture $75 \%$ of the area being designated as inundated by the 100-year flood inundation map. The specificity $\left(S_{c}\right)$ was found to be higher at 0.85 indicating that the hazard map could be reliably used to identify an area that would not be inundated by a 1-in-100-year flood as determined by the inundation map. The locations where the discrepancy between the two maps exist can be identified visually. The most noticeable disagreement between the hazard map and the inundation map is just above the confluence of the Bow and Elbow rivers, where the severe hazard level is much wider than the modelled extent. The scrutiny of areal imagery of that area did not indicate the presence of any flood protection measures at that location. A specific reason could not be ascertained to explain the discrepancy, which could vary from the incorrectness of the DEM at that location to the modelling extent of the hydraulic model used to prepare the inundation map. Interestingly, a similar observation for the same location was made by Sampson et al. (2015) in 


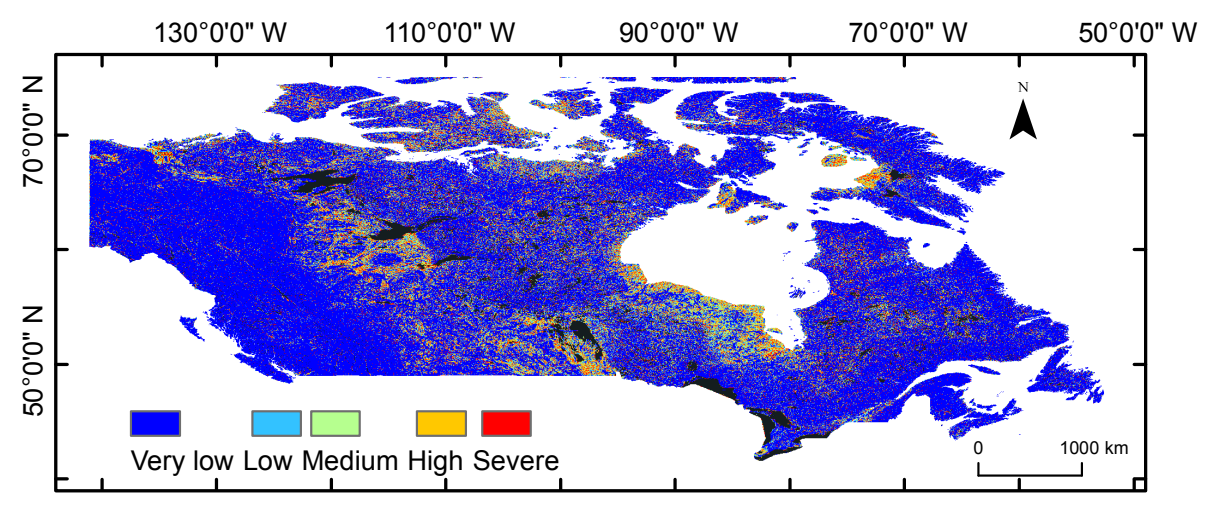

Figure 3. Flood hazard map for Canada obtained using the $20 \mathrm{~m}$ DEM. Large areas are classified under high- and severe-level flood hazard, but most areas have negligible human presence and investments.

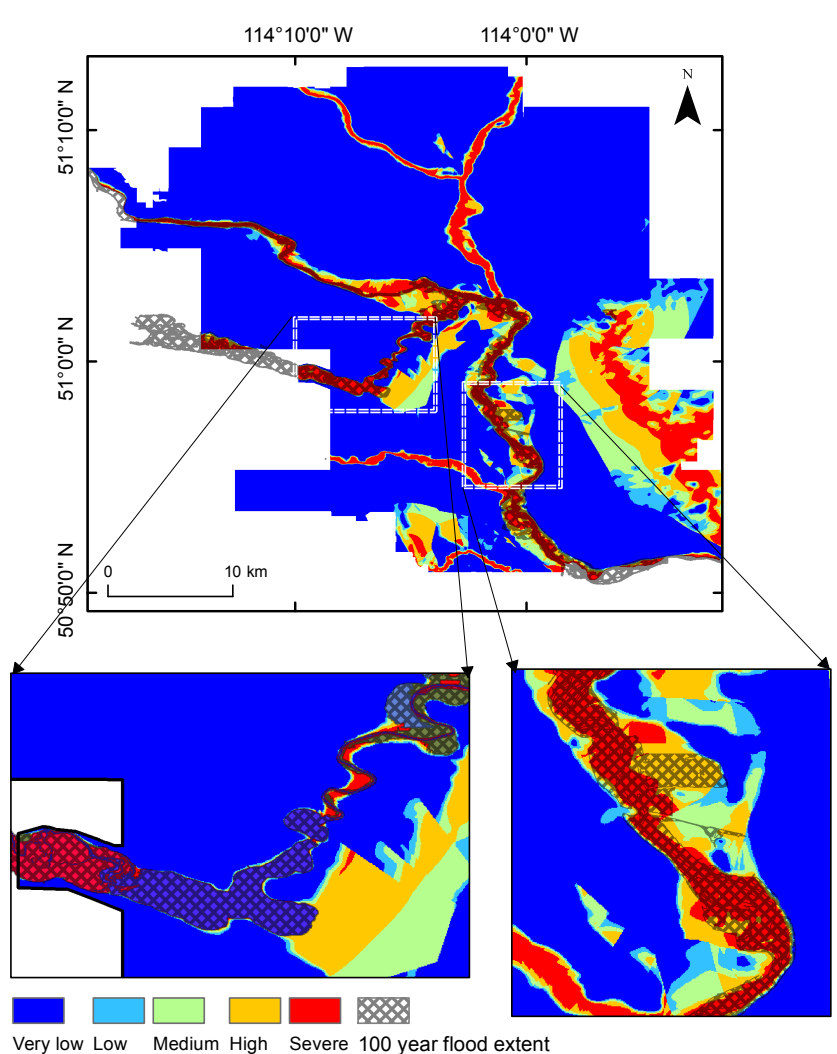

Figure 4. Comparison of hazard map obtained from the present study and a 100-year-flooding extent map prepared by the city of Calgary (hatched portions). Portions of the reach along the Bow and Elbow rivers are enlarged to show the level of agreement between both maps.

their study, wherein their global hydraulic model also overestimated the inundation extent at the same location.

The hazard levels can be reclassified locally based on different values of EAND and DFND to match particular floods, e.g. 100-year or 200-year, in areas where flood inundation using hydraulic modelling is available. This way, the flood haz-

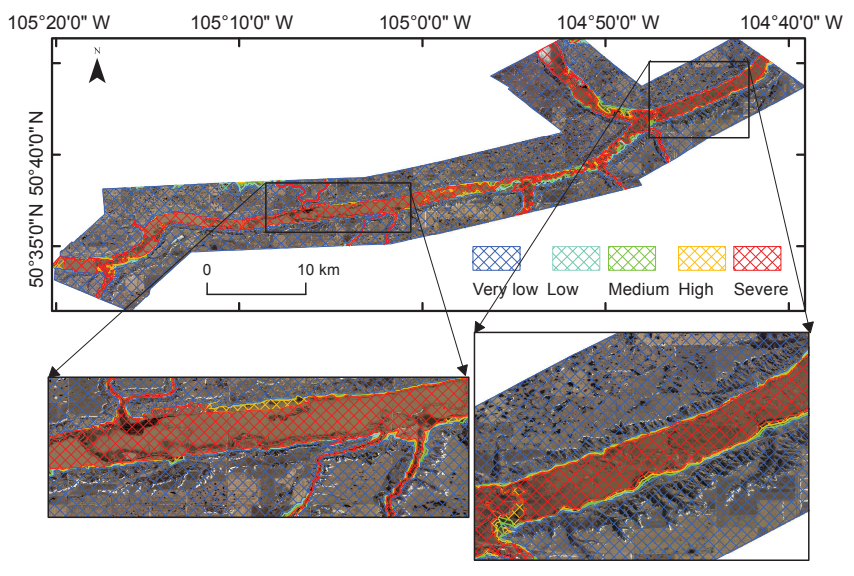

Figure 5. Comparison of hazard map with aerial image of a single flood event on the Qu'Appelle River, Saskatchewan (background). Date of image: 6 May 2013.

ard map can be converted into approximate flood inundation maps for floods with particular return periods. To check if the hazard map can be compared against an observed flood, a qualitative analysis was also done by visually comparing the hazard map with an aerial imagery of the 2013 flood in the Qu'Appelle River located in the Saskatchewan province of Canada (Fig. 5). The image was taken on 6 May 2013, a day after the annual maximum discharge was recorded in the river and the flooded extent is visible in the image. To compare across both maps, the hazard map is overlaid as a mesh on the aerial image. It can be observed from the figure that the flooding extent is well captured by the hazard level severe at most locations along the reach. This result further strengthens the relevance of the hazard map and its accuracy in identifying flooding extents.

Another important flood hazard parameter, which was not fully implemented here due to lack of information, is flood protection measures. However, an example using an area near the city of Winnipeg, Manitoba, is shown in Fig. 6. The 


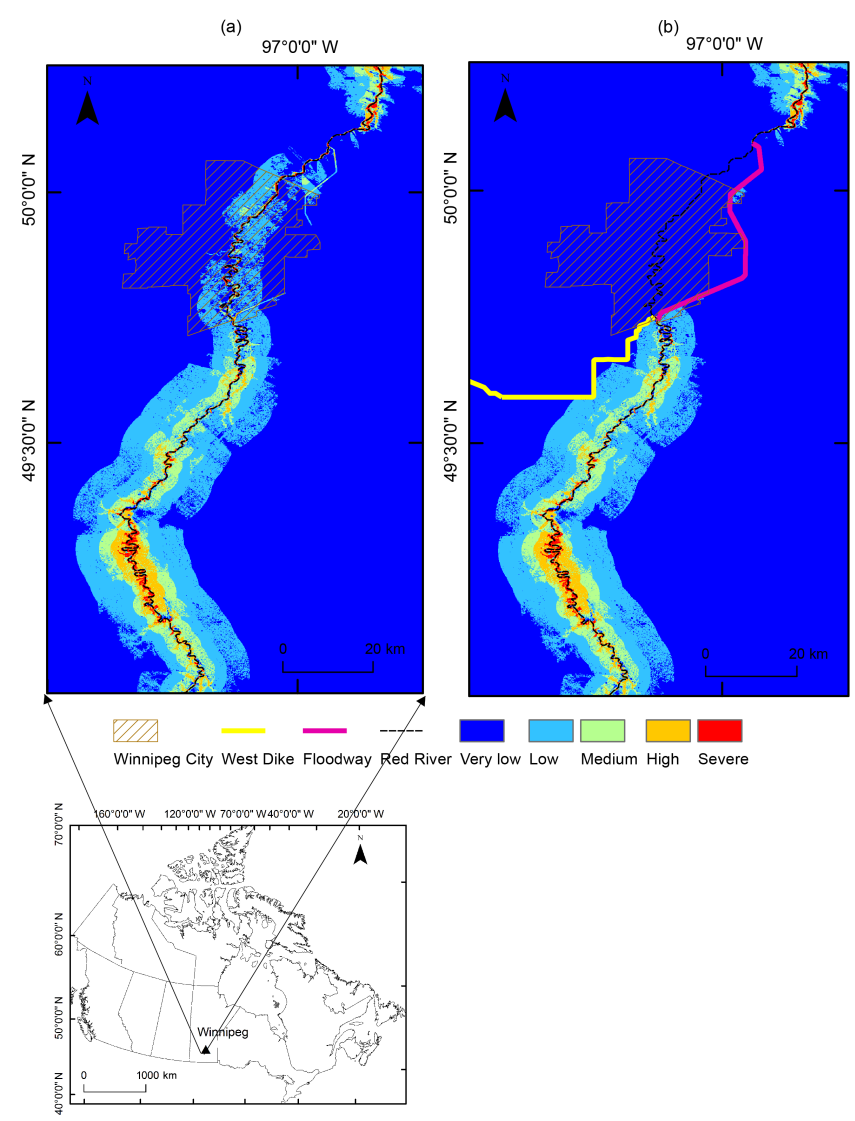

Figure 6. Hazard map for the Red River in Manitoba: (a) without considering flood protection structures in delineating hazard zones and (b) considering flood protection.

city of Winnipeg is protected from Red River floods using a floodway (appears in the figure in pink colour) that carries part of the flood runoff around the city, and a dike (appears in the figure in yellow colour) that prevents flood surface runoff from entering the city from the west side. The effect of flood protection of these structural measures is handled in our flood hazard mapping method by identifying the flood depth up to which the city is protected (flood design level), then assigning the design level to the DEM cells in the protected area. A hazard map with and without flood protection for the city of Winnipeg is provided in Fig. 6, which shows the reduced level of flood hazard within the city limits. Usually, there are backwater and other hydraulic effects on areas upstream of flood protection, and such effects cannot be easily captured by the topography-based hazard mapping adopted here. Hydraulic modelling is recommended to investigate the effects of flood protection measures on upstream unprotected areas.

\subsection{Flood exposure and risk mapping}

The flood exposure map of Canada, which integrates landuse and nightlight information, is shown as Fig. 7. The areas of higher exposure are mainly concentrated around ma- jor urban centres in Canada. As expected, the exposure map is quite similar to the nightlight map (Fig. 2b), because the distribution of nightlight matches to a great extent the landuse map; for example, urban areas are much more luminous than forests. However, it is useful to include both types of information as some major capital investments, reflected by high luminosity, can be situated within larger areas classified as agricultural or forested areas. To demonstrate this, a small area within the exposure map is enlarged and overlaid with the road network map obtained from the National Road Network (http://geogratis.gc.ca/) and shown in Fig. 7. Although the exposure indicates "very low" to "low", the hazard map for the same location indicates a significant area within the "severe" and "high" classes. Roads were flooded in major Canadian flood events and hampered rescue efforts. Also, some large parks with lower luminosity can be found within the limits of urban areas. Furthermore, nightlights are quantified using the DN, which helps in using them as a proxy for economic investment/damage calculations in the absence of monetary values. It is important to note that one of the shortcomings of using nightlights is the phenomenon of "overglow" (Doll, 2008) - areas of low luminosity shown with false high luminosity due to reflections from surrounding areas with much higher luminosity. Small et al. (2005) listed three major causes for this phenomenon: coarse spatial resolution, large overlap between pixels, and errors in the geolocation.

By assuming that flood vulnerability is homogeneous over Canada, a flood risk map of Canada, which results from the product of flood hazard and exposure only, is shown in Fig. 8. Even though severe and high flood hazard areas are spread spatially over the entire country, severe and high flood-risk areas are concentrated in urban centres in the southern part of Canada. Severe and high flood hazards in northern areas assume lower levels of risk when integrated with lower levels of exposure in the north due to lack of human activities and urban centres. These maps are in $20 \mathrm{~m}$ resolution, which allows for assessing the flood hazard, exposure, and risk in details, which are not visible on a national map.

A key flood exposure and risk parameter, which was deliberately left out of the risk map, is population. Using the example of the Greater Toronto Area in Ontario, Fig. 9 shows the differences that are represented by nightlights, population distribution, and land-use maps. The airport area, indicated by a grey triangle, and an industrial area indicated by a grey circle, are typical examples of urban/built-up areas (Fig. 9c) with high economic investments that are highly luminous areas (Fig. 9a), but very low - close to zero - population (Fig. 9b). This confirms that nightlights and population distribution can differ at times, and it is important to include both parameters, but without integrating them in order to avoid the "average" effect.

To identify flood impact on people (social impact) and separate it from economic impact, we propose overlaying the flood risk map (Fig. 8) with a population density layer. Fig- 


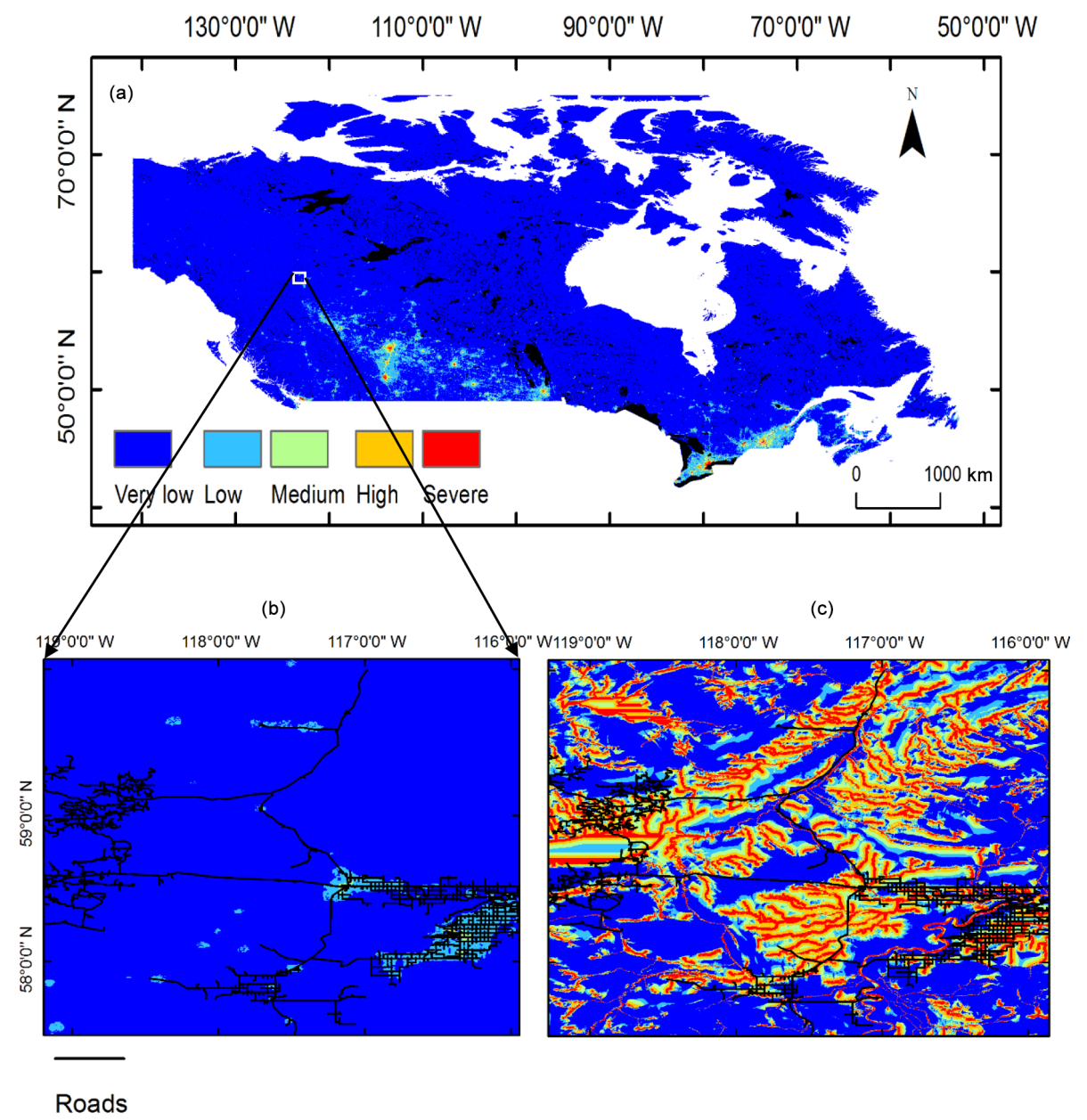

Figure 7. Classified flood exposure map for Canada. Severe and high exposure are concentrated around urban centres in the southern part of the country. Enlarged portion shows road network overlaid over (a) exposure map and (b) hazard map.

ure 10 shows an example of such reclassification of the flood risk map with and without population on a smaller area (the city of Calgary, Alberta) for better visualisation of the concept. The central part of the city with high-rise buildings and high population density remains within the highest levels of flood risk where both economic and social risks are at their highest levels. The northern and southern parts, which are mainly commercial areas with lower population density and, thus, lower social risk, assume reduced levels of overall flood risk (Fig. 10b) in spite of having severe economic flood risk (Fig. 10a).

\section{Discussion}

Even though flood hazard, exposure, and vulnerability maps are all important, the flood hazard map is of special interest to both the public and planners or decision makers. The flood hazard map allows the public to assess the situation of their properties with respect to floods, whether the prop- erty is residence, agricultural land, or commercial business. For planners and decision makers, flood hazard maps allow for assessing areas of future development, or locations of strategic establishments. As mentioned earlier, the flood hazard map developed in this study can be reclassified or converted to inundation maps of floods with specific return periods, e.g. 100-year flood, using hydraulic modelling, or even linked to particular recorded flood events, such as the known 1979, 1997, and 2011 floods in Manitoba. In some areas, like the city of Calgary (Fig. 4), 100-year flood extent almost matches our severe flood hazard class $(<2 \mathrm{~m})$. In other regions, and depending on the topography, the 100-year flood might cover two or three of the flood hazard classes. Furthermore, local authorities may relate flows at different flood frequencies (e.g. 100 year) to water stage (can be done using rating curves available locally). The stages of different floods indicate clearly which of the hazard classes, determined using the topography-based hazard mapping, will be inundated. This way local authorities can convert the flood hazard map to flood frequencies. 


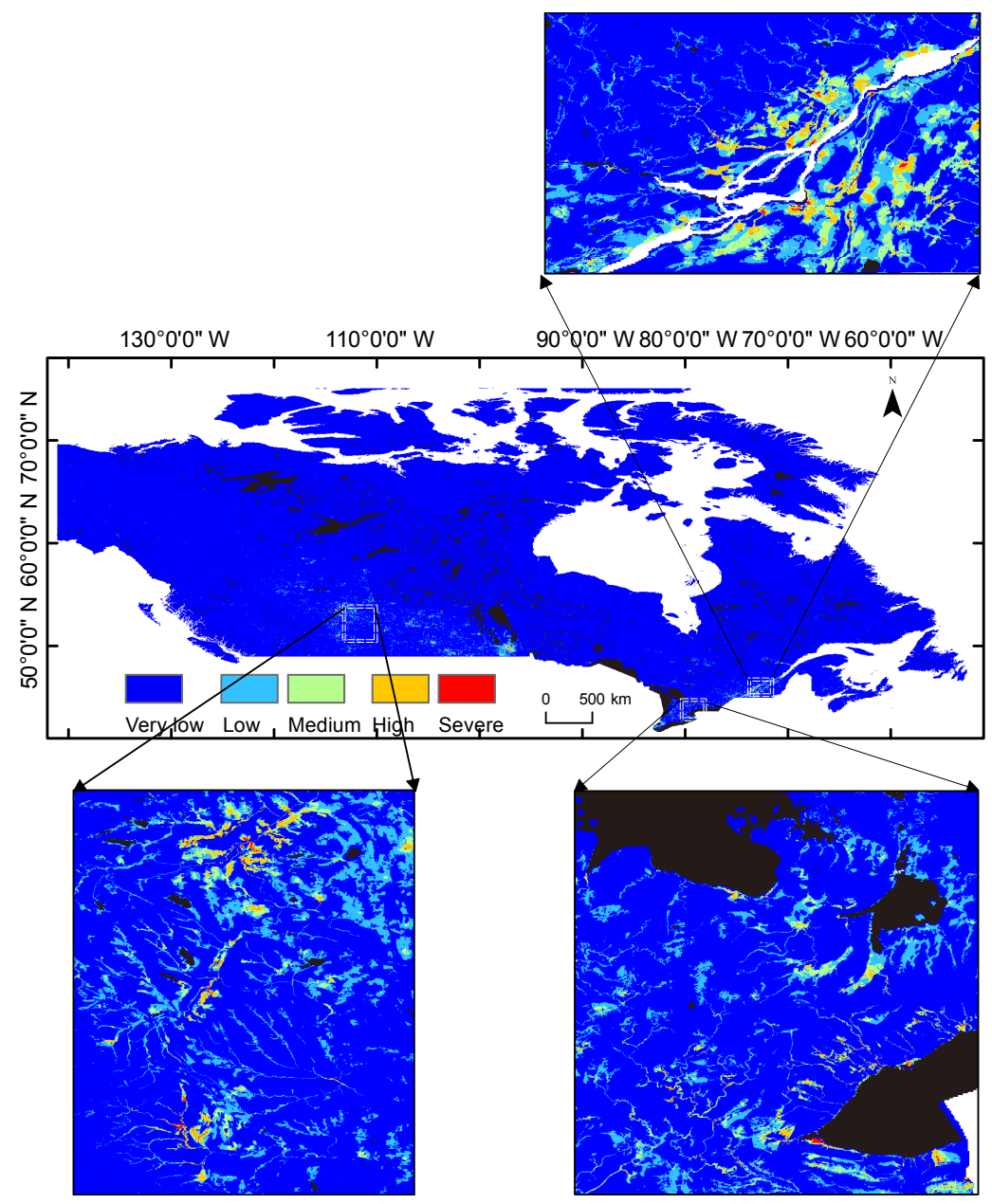

Figure 8. Flood risk map for Canada. Certain portions of the map are enlarged for better visual interpretation of the various levels of flood risk. The risk map is a product of hazard and exposure (flood protection measures are not included). Severe risk only occurs in areas of severe hazard and exposure, causing severe flood risk areas to be concentrated in urban centres.

For prioritizing resource allocation and intervention for flood damage mitigation, flood risk is the important indicator as it integrates hazard, exposure, and vulnerability, and reflects the spatial distribution of expected damage. The general flood risk map, similar to Figs. 8 and 10a, can be used for prioritizing intervention and estimating compensations based on economic flood risk, but flood risk maps with population, similar to Fig. 10b, add an important sociopolitical dimension because they indicate where certain levels of risk affect more or fewer people. This type of socioeconomic flood risk map can be made public to collect feedback from all stakeholders. Certain groups falling under reduced levels of risk may raise issues of particular social exposure or vulnerability, and help water managers revise the classification or use differential spatial weights to produce more realistic socioeconomic flood risk maps. This approach of engaging both the public and water professionals in co-production of floodrelated knowledge can be initiated using the risk maps (Lane et al., 2011).
The simple way presented in this paper for considering the effect of flood protection on the hazard (or vulnerability), and thus the risk, classification can be useful for quantifying the change in the spatial distribution of flood risk. This might prove useful for comparing flood risk with different types of societal risk, e.g. forest fires. This method allows for quick assessment of the value of flood protection measures, and the locations of critical need for such measures.

It is important to note that there are various uncertainties associated with the nightlight and topography-based approach suggested in this paper for flood risk assessment in Canada. The DEM's resolution is an important criterion, and sensitivity analysis might be needed to identify a resolution that is coarse enough for tractable computations, but fine enough for reliable identification of the stream network and the various hazard classes. The available nightlight data are of much coarser resolution $(1 \mathrm{~km})$ than the required DEM's resolution. This difference, along with the uncertainty stemming from the overglow phenomenon, can cast some doubts 
(a)

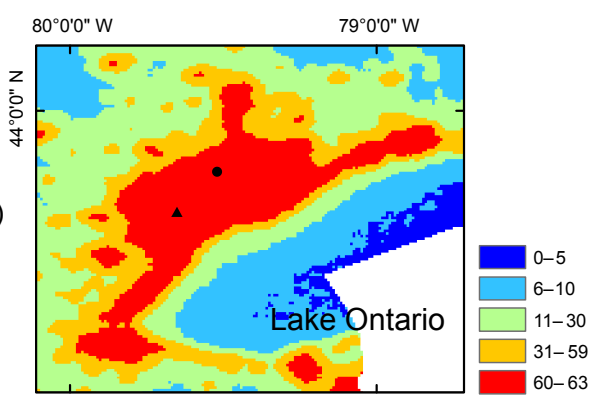

(b)

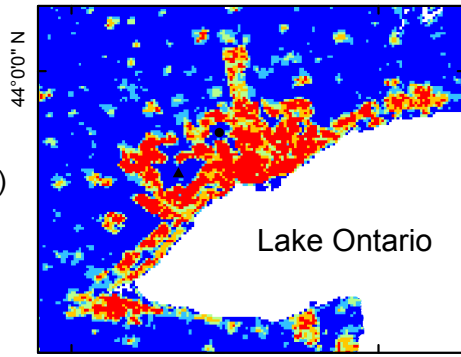

Population density (No. of persons $\mathrm{m}^{-2}$ )
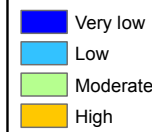

High

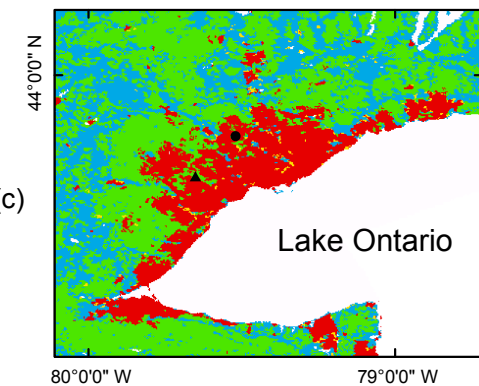

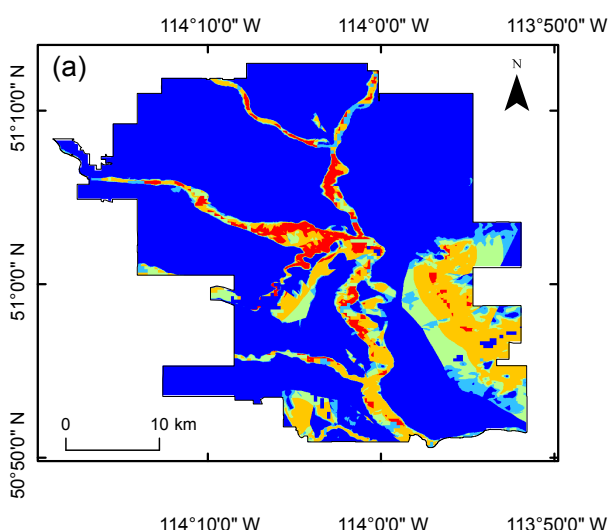

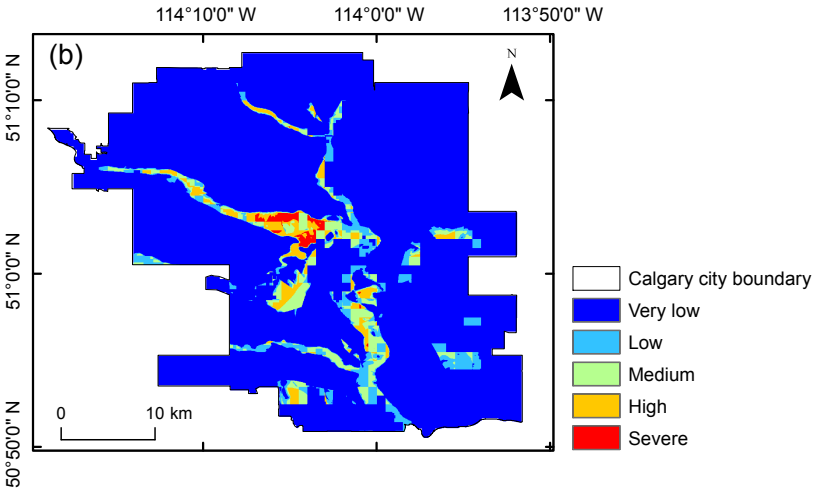

Figure 10. Flood risk map of Calgary: (a) without population information, and (b) with population. Areas around the centre of the city with high rises and dense population remain in the severe risk category, whereas northern and southern parts, which are mainly commercial, change to reduced levels of social risk.

preliminary assessment of the flood hazard level anywhere in the country. This low-cost product can be used for early stages of development planning. Identifying the flood hazard level of even areas such as wastelands might prove useful for planning and management of activities like mining in remote and undeveloped areas. The flood risk map, which integrates both hazard and exposure, including nightlights, is the most useful product as it allows for evaluating the spatial distribution of the expected flood damage, and thus can help in prioritizing government intervention and strategic resource allocation. The risk map, which typically reflects economic risk can be combined with population distribution maps to explicitly identify the social risk dimension as well as overall socioeconomic flood risk. It was shown in this study that nightlight luminosity and population distribution can differ at certain locations, and it is beneficial to use both types of information for flood risk assessment.

The severe and high flood hazard areas in Canada are spread over all regions of the country; however, the severe and high flood exposure and risk are concentrated in the southern part of the country around urban centres. Complete information on flood protection across Canada should be collected and integrated with the developed hazard and 
risk maps produced in this study in order for these products to be considered complete and ready to use. Some sensitivity analysis regarding the required DEM's resolution is needed to identify the resolution that is fine enough for reliable hazard mapping, but coarse enough for computational tractability. Both the DEM's resolution and the nightlight's overglow phenomenon are possible sources of uncertainty in the maps produced in this study. Attempts should be made in the future to quantify such levels of uncertainty.

Data availability. The Nightlight data were obtained from http://ngdc.noaa.gov/eog/dmsp/downloadV4composites.html

(NOAA, 2013). The digital elevation model data were obtained from http://geogratis.gc.ca/site/eng/extraction (Natural Resources Canada, 2013). The Landuse data were obtained from http://www.cec.org/tools-and-resources/ map-files/land-cover-2005 (Commission for Environmental Cooperation, 2013). The population data used here were obtained from http://sedac.ciesin.columbia.edu/data/set/ gpw-v4-population-density-adjusted-to-2015-unwpp-country-totals/ data-download\#close (CIESIN, 2016).

Competing interests. The authors declare that they have no conflict of interest.

Acknowledgements. The financial support of NSERC through the strategic research network - FloodNet - and the Discovery Grant program is acknowledged. S. Ceola and A. Montanari gratefully acknowledge the financial support from the FP7 EU funded project SWITCH-ON (grant agreement no. 603587).

Edited by: G. Di Baldassarre

Reviewed by: two anonymous referees

\section{References}

Adger, W.: Social vulnerability to climate change and extremes in coastal Vietnam, World Dev., 27, 249-269, 1999.

Adger, W.: Vulnerability, Global Environ. Chang., 16, 268-281, 2006.

Altman, D. G. and Bland, J. M.: Diagnostic tests. 1: Sensitivity and specificity, Brit. Med. J., 308, 1552-1552, 1994.

Apel, H., Aronica, G., Kreibich, H., and Thieken, A.: Flood risk analyses - how detailed do we need to be?, Nat. Hazards, 49, 79-98, 2009.

Balica, S., Popescu, I., Beevers, L., and Wright, N.: Parametric and physically based modelling techniques for flood risk and vulnerability assessment: A comparison, Environ. Model. Soft., 41, 8492, 2013.

Biondi, D., Freni, G., Iacobellis, V., Mascaro, G., and Montanari, A.: Validation of hydrological models: Conceptual basis, methodological approaches and a proposal for a code of practice, Phys. Chem. Earth, 42-44, 70-76, 2012.
Brakenridge, R. and Anderson, E.: MODIS-based flood detection, mapping and measurement: the potential for operational hydrological applications, in: Transboundary Floods: Reducing Risks Through Flood Management, edited by: Marsalek, J., Stancalie, G., and Balint, G., Springer, the Netherlands, 1-12, 2006.

Ceola, S., Laio, F., and Montanari, A.: Satellite nighttime lights revealing increased human exposure to floods worldwide, Geophys. Res. Lett., 41, 7184-7190, doi:10.1002/2014GL061859, 2014.

Ceola, S., Laio, F., and Montanari, A.: Human-impacted waters: New perspectives from global highresolution monitoring, Water Resour. Res., 51, 7064-7079, doi:10.1002/2015WR017482, 2015.

CIESIN (Center for International Earth Science Information Network): Columbia University, Gridded Population of the World, Version 4 (GPWv4), Population Density Adjusted to Match 2015 Revision UN WPP Country Totals, Palisades, NY, NASA Socioeconomic Data and Applications Center (SEDAC), available at: http://sedac.ciesin.columbia.edu/data/set/gpw-v4-populationdensity-adjusted-to-2015-unwpp-country-totals, last access: December 2016.

Collenteur, R. A., de Moel, H., Jongman, B., and Di Baldassarre, G.: The failed-levee effect: Do societies learn from flood disasters?, Nat Hazards, 76, 373-388, doi:10.1007/s11069-014-14966, 2015.

Commission for Environmental Cooperation: North American Land Change Monitoring System, Land cover data, available at: http://www.cec.org/tools-and-resources/map-files/ land-cover-2005 (last access: December 2016), 2013.

Cutler, D. R., Edwards, T. C., Beard, K. H., Cutler, A., Hess, K. T., Gibson, J., and Lawler, J. J.: Random forests for classification in ecology, Ecology, 88, 2783-2792, doi:10.1890/07-0539.1, 2007.

de Moel, H., van Alphen, J., and Aerts, J. C. J. H.: Flood maps in Europe - methods, availability and use, Nat. Hazards Earth Syst. Sci., 9, 289-301, doi:10.5194/nhess-9-289-2009, 2009.

Di Baldassarre, G., Viglione, A., Carr, G., Kuil, L., Yan, K., Brandimarte, L., and Bloschl, G.: Debates - Perspectives on socio-hydrology: Capturing feedbacks between physical and social processes, Water Resour. Res., 51, 4770-4781, doi:10.1002/2014WR016416, 2015.

Doll, C.: CIESIN thematic guide to night-time light remote sensing and its applications, Center for International Earth Science Information Network of Columbia University, Palisades, NY, 2008.

Doll, C., Muller, J. P., and Elvidge C.: Night-Time Imagery as a Tool for Global Mapping of Socio-Economic Parameters and Greenhouse Gas Emissions, AMBIO, 29, 157-162, 2000.

Famiglietti, J. S. and Rodell, M.: Water in the balance, Science, 340, 1300-1301, 2013.

Gilard, O.: Hazard, vulnerability, and risk, in: Climate Change and Agriculture Worldwide, edited by: Torquebiau, E., Éditions Quæ, France, 19-29, 2016.

Gómez, A. J. S., Di Baldassarre, G., Rodhe, A., and Pohjola, V. A.: Remotely Sensed Nightlights to Map Societal Exposure to Hydrometeorological Hazards, Remote Sensing, 7, 12380-12399, 2015.

Government of Alberta: Flood hazard studies, available at: http://aep.alberta.ca/water/programs-and-services/ flood-hazard-identification-program/flood-hazard-studies/ default.aspx (last access: December 2016), 2013. 
Hall, J., Sayers, P., and Dawson, R.: National-scale assessment of current and future flood risk in England and Wales, Nat. Hazards, 36, 147-164, 2005.

IPCC (Intergovernmental Panel on Climate Change): Glossary of terms, in: Managing the Risks of Extreme Events and Disasters to Advance Climate Change Adaptation, edited by: Field, C. B., Barros, V., Stocker, T. F., Qin, D., Dokken, D. J., Ebi, K. L., Mastrandrea, M. D., Mach, K. J., Plattner, G.-K., Allen, S. K., Tignor, M., and Midgley, P. M., A Special Report of Working Groups I and II of the Intergovernmental Panel on Climate Change (IPCC), Cambridge University Press, Cambridge, UK, and New York, NY, USA, 555-564, 2012.

Jenson, S. K. and Domingue, O. J.: Extracting topographic structure from digital elevation data for geographic information system analysis, Photogramn. Engg. Rem. S, 54, 1593-1600, 1988.

Jonkman, S.: Global perspectives on loss of human life caused by floods, Nat. Hazards, 34, 151-175, 2005.

Lane, S. N., Odoni, N., Landström, C., Whatmore, S. J., Ward, N., and Bradley, S.: Doing flood risk science differently: an experiment in radical scientific method, Trans. Inst. Br. Geogr., 36, 15-36, 2011.

Latifovic, R., Homer, C., Ressl, R., Pouliot, D., Hossain, S. N., and Colditz, R. R.: North American land-change monitoring system, edited by: Giri, C. P., Remote sensing of land Use and land cover: Principles and applications, CRC/Taylor \& Francis, Boca Raton, Fl, 303-324, 2012.

Lugeri, N., Kundzewicz, Z., Genovese, E., Hochrainer, S., and Radziejewski, M.: River flood risk and adaptation in Europe assessment of the present status, Mitig. Adapt. Strateg. Glob. Change, 15, 621-639, 2010.

Masood, M. and Takeuchi, K.: Assessment of flood hazard, vulnerability and risk of mid-eastern Dhaka using DEM and 1D hydrodynamic model, Nat. Hazards, 61, 757-770, 2012.

Mays, L. W.: Flood Control, in: Water Resources Engineering, Chapter 14, 2nd ed., John Wiley and Sons, New Jersey, USA, 2015.

Merz, B., Hall, J., Disse, M., and Schumann, A.: Fluvial flood risk management in a changing world, Nat. Hazards Earth Syst. Sci., 10, 509-527, doi:10.5194/nhess-10-509-2010, 2010.

Milly, P., Wetherald, R., Dunne, K., and Delworth, T.: Increasing risk of great floods in a changing climate, Nature, 415, 514-517, 2002.

Murtaugh, P. A.: The Statistical Evaluation of Ecological Indicators, Ecol. Appl., 6, 132-139, doi:10.2307/2269559, 1996.

Natural Resources Canada: Geospatial Data Extraction, available at: http://geogratis.gc.ca/site/eng/extraction (last access: December 2016), 2013.

Natural Resources Canada: Canadian Digital Elevation Model Product Specifications, Edition 1.1, Quebec, Canada, 18 pp., 2016.

National Research Council Canada (NRCC): Hydrology of floods in Canada: A guide to planning and design, NRCC no. 29734, Ottawa, Canada, 245 pp., 1989.
NOAA: Earth Observation Group, Version 4 DMSP-OLS Nighttime Lights Time Series, available at: https://ngdc.noaa.gov/ eog/dmsp/downloadV4composites.html (last access: December 2016), 2013.

Parajka, J. and Blöschl, G.: The value of MODIS snow cover data in validating and calibrating conceptual hydrologic models, J. Hydrol., 358, 240-258, 2008.

Raupach, M. R., Rayner, P. J., and Paget, M.: Regional variations in spatial structure of nightlights, population density and fossil-fuel $\mathrm{CO}_{2}$ emissions, Energy Policy, 38, 4756-4764, 2010.

Rennó, C., Nobre, A., Cuartas, L., Soares, J., Hodnett, M., Tomasella, J., and Waterloo, M.: HAND, a new terrain descriptor using SRTM-DEM: Mapping terra-firme rainforest environments in Amazonia, Remote Sens. Environ., 112, 3469-3481, 2008.

Sampson, C. C., Smith, A. M., Bates, P. D., Neal, J. C., Alfieri, L., and Freer, J. E.: A high-resolution global flood hazard model, Water Resour. Res., 51, 7358-7381, 2015.

Samuels, P.: Language of risk: project definitions, Report no. T3204-01, Integrated Flood Risk Analysis and Management Methodologies, HR Wallingford, 2009.

Sanders, R., Shaw, F., MacKay, H., Galy, H., and Foote, M.: National flood modelling for insurance purposes: using IFSAR for flood risk estimation in Europe, Hydrol. Earth Syst. Sci., 9, 449456, doi:10.5194/hess-9-449-2005, 2005.

Sayers, P. B., Hall, J. W., and Meadowcroft, I. C.: Towards riskbased flood hazard management in the UK, P. I. Civil Eng., 150, 36-42, 2002.

Small, C., Pozzi, F., and Elvidge, C. D.: Spatial analysis of global urban extent from DMSP-OLS night lights, Remote. Sens. Environ., 96, 277-291, 2005.

Townsend, A. C. and Bruce, D. A.: The use of night-time lights satellite imagery as a measure of Australia's regional electricity consumption and population distribution, Int. J. Remote Sens., 31, 4459-4480, 2010.

UNISDR (United Nations International Strategy for Disaster Reduction): Terminology on Disaster Risk Reduction, Geneva, Switzerland, 2009.

Ward, P. J., Jongman, B., Weiland, F. S., Bouwman, A., van Beek, R., Bierkens, M. F., Ligtvoet, W., and Winsemius, H. C.: Assessing flood risk at the global scale: model setup, results, and sensitivity, Environ. Res. Lett., 8, 1-10, doi:10.1088/17489326/8/4/044019, 2013

Whitfield, P. H. and Cannon, A. J.: Recent variations in climate and hydrology in Canada, Can. Wat. Res. J., 25, 19-65, 2000.

Zhou, Y., Smith, S. J., Elvidge, C. D., Zhao, K., Thomson, A., and Imhoff, M.: A cluster-based method to map urban area from DMSP/OLS nightlights, Remote Sens. Environ., 147, 173-185, 2014. 